\title{
Gastrointestinal Stromal Tumors: Clinical Symptoms, Location, Metastasis Formation, and Associated Malignancies in a Single Center Retrospective Study
}

\author{
Ali Aghdassi $^{\mathrm{a}}$ Agnes Christoph $^{\mathrm{a}}$ Frank Dombrowski $^{\mathrm{b}}$ Paula Döring ${ }^{\mathrm{b}}$ \\ Christoph Barth $^{c}$ Jan Christoph ${ }^{d}$ Markus M. Lerch ${ }^{a}$ Peter Simon $^{\text {a }}$

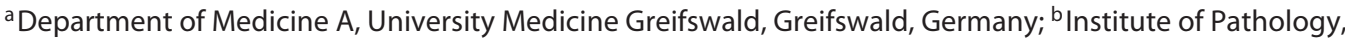 \\ University Medicine Greifswald, Greifswald, Germany; ${ }^{\mathrm{C}}$ Gastroenterologische Praxis, Kempten, Germany; \\ ${ }^{\mathrm{d}}$ Chair of Medical Informatics, Friedrich-Alexander-University Erlangen-Nürnberg, Erlangen, Germany
}

\section{Keywords}

Gastrointestinal stromal tumor · Gastrointestinal oncology · Gastrointestinal symptoms · Gastrointestinal tract $\cdot$ Metastasis $\cdot$ Recurrence

\begin{abstract}
Background and Aims: Gastrointestinal stromal tumors (GISTs) are rare malignancies but the most common mesenchymal tumors of the digestive tract. Recent advances in diagnostic imaging and an increasing incidence will confront us more frequently with stromal tumors. This single center study aimed to characterize GIST patients in terms of tumor location, clinical presentation, metastasis formation, as well as associated secondary malignancies. Methods: In a retrospective study, 104 patients with a histologically confirmed diagnosis of GIST, collected between 1993 and 2011, were characterized for several clinical features. Results: The most common GIST location was the stomach (67.6\%) followed by the small intestine (16.2\%). Gastrointestinal bleeding (55.8\%) and abdominal pain (38.5\%) were the most frequently reported symptoms whereas about one-third of patients remained clinically asymptomatic (31.6\%); $14.4 \%$ of patients had either synchronous or metachronous metastases and
\end{abstract}

(C) 2018 S. Karger AG, Basel

\section{E-Mail karger@karger.com} www.karger.com/ddi there was a significant prevalence also in the low risk group. The proportion of secondary malignant associated neoplasms was $31 \%$ in our GIST cohort, among which gastrointestinal, genitourinary tumors, and breast cancer were the most prevalent. Conclusion: There was a considerable risk for metastasis formation and the development of secondary neoplasias that should encourage discussion about the appropriate surveillance strategy after surgery for GIST.

(c) 2018 S. Karger AG, Basel

\section{Introduction}

With only $0.1-3 \%$ of all gastrointestinal neoplasms, gastrointestinal stromal tumors (GISTs) are a rare tumor entity. Nonetheless they represent the most common mesenchymal tumors of the digestive tract and are even found in extraintestinal locations (eGIST) [1,2]. Arising from the interstitial cells of Cajal or their precursors, they show a set of characteristic features including a spindle cell, epithelioid or, rarely, a pleomorphic morphology.

\section{A.A. and A.C. are both first authors.}

Markus M. Lerch, MD, FRCP 
Mutations in the genes for cKIT (CD117; 85\% of all GIST) and platelet-derived growth factor receptor alpha (5-7\%) were ascribed a central role in the pathogenesis by permanent tyrosine kinase activation [3-5].

The annual incidence of GISTs ranges from 0.7 to 2 per 100,000 and increased during the last years $[6,7]$. Data from the Surveillance, Epidemiology, and End Results registry from the U.S. National Cancer Institute found an age-adjusted yearly incidence of 6.8 per million $[8,9]$.

Several risk classifications systems exist for stratification of stromal tumors such as those by Fletcher et al. [10], the modified National Institutes of Health (NIH) classification by Joensuu et al. [11], or the TNM-classification [12]. The ESMO guidelines favor the use of a classification by the Armed Forces Institute of Pathology (AFIP) [6] that considers tumor size, location, and their mitotic rate as prognostic factors [13]. Modified NIH criteria encompass a fourth factor, which is tumor rupture [14].

In early stages, stromal tumors often remain asymptomatic and are detected accidentally. Clinical symptoms vary and include gastrointestinal bleeding (51\%), a palpable mass (36\%), and abdominal pain (33\%) whereby the stomach is the most common site of disease manifestation followed by the small intestine [15]. Usually diagnosis is achieved using a combination of endoscopy, laparoscopy, and computed tomography [6]. Treatment options are manifold depending on the size and location of the tumor, localized or metastasized disease status, age, and comorbidities of the patient and include surgical and medical procedures. Standard treatment comprises surgical excision unless oncologic resection is feasible and no major comorbidity exists. In case of a high estimated risk for GIST recurrence after surgery, adjuvant therapy with tyrosine kinase inhibitors (imatinib) is initiated [16]. Mutational analysis is critical as some genotypes limit the success of adjuvant therapy such as in platelet-derived growth factor receptor alpha D842V-mutated GISTs. In locally advanced and metastasized stages, imatinib is the standard treatment and dose modification may be required according to the genotype of the KIT gene. In case of tumor progression or intolerance, sunitinib and regorafenib are considered as second- and third-line treatment options $[6,17,18]$.

As known for other malignant tumors, GISTs harbor a risk of relapse and metastasis formation [19]. Secondary tumors, mainly gastrointestinal malignancies, have been reported in association with stromal tumors, which further worsen prognosis [20,21].

Here, we present data on GIST patients that were diagnosed in a single center in Western Pommerania, a rural region of Germany, in a time period from 1993 to
2011. We focused on clinical symptoms and their presence depending on tumor location. Secondly, we investigated the occurrence of metastases and the prevalence of associated secondary tumors.

\section{Patients and Methods}

Selection of Patients

After ethical approval from the local institutional review board committee, we collected clinicopathological and follow-up data of patients with the diagnosis of a GIST at University Medicine Greifswald in a retrospective monocentric analysis between 1993 and 2011. Patients were identified in the hospital information system using the ICD-10 codes C15 to C18 and C48. and via cross-checking of histology reports of the Institute of Pathology. A total of 104 patients were identified with residence in Western Pomerania (urban district of Greifswald, Vorpommern-Greifswald, Vorpommern-Rügen, and Mecklenburg-Lake counties). The diagnosis of GIST was histologically confirmed for all patients and was done in all cases by the Institute of Pathology of University Medicine Greifswald. From 1993 to 1998, diagnosis of GIST was established retrospectively because this tumor was defined as an independent entity in 1998 [22]. Tumors were immune-stained for CD117, CD34, and smooth muscle antigen. Specimens from 1993 to 1998 were retrospectively stained with CD117 and CD34. The number of residents in Western Pomerania (the same catchment area) was obtained from the statistical office of Mecklenburg-Western Pomerania based on the census of 2013 [23]. The number of inhabitants was 727,270 on January 1, 2013.

\section{Acquisition of Clinical Data and Statistical Analysis}

After identification of patients, they were contacted by mail and informed about the intention and type of study. A written informed consent was obtained from all still living individuals. In those patients who already died, consent was obtained by proxy and data fully anonymized. Patient data included gender, age at diagnosis of GIST, clinical symptoms, size, localization and genotype of the tumor, diagnostic examinations performed, therapy, and follow-up data. Histological subtypes of GIST and proliferation index were assessed, too. Risk of tumor recurrence was stratified according to the AFIP-Miettinen classification system, the Fletcher consensus criteria, and the modified NIH classification by Joensuu, whenever possible. Results were reported as percentages, mean \pm SD, and median and range, when applicable. A 2 -tailed $p$ value of $<0.05$ was considered to be significant. Data were collected using Microsoft ${ }^{\circledR}$ Access 2013 (Redmond, WA, USA) software and have been analyzed by the translational research platform tranSMART in version 16.2 [24].

\section{Results}

\section{Characterization of the Cohort and Pathology} of the Tumor

The study included 104 patients showing an almost equal distribution of female (48.1\%) and male (51.9\%) patients. Mean age of first diagnosis of GIST was 66.86 years 
Table 1. Characterization of the study group

\begin{tabular}{lc}
\hline Quality & Results \\
\hline Age and gender & \\
Patients with diagnosis of GIST & 104 \\
Age at diagnosis, years, mean \pm SD (range) & $66.86 \pm 11.85(30-88)$ \\
Males, $n$ (\%) & $54(51.9)$ \\
Tumor size and histology & 94 \\
Tumor diameter available & $4.96 \pm 3.85(0.2-20)$ \\
Tumor size, cm, mean \pm SD (range) & 93 \\
Histology available & $72(77.4)$ \\
Spindle cell, $n(\%)$ & $12(12.9)$ \\
Epithelioid cell, $n$ (\%) & $9(9.7)$ \\
Mixed type, $n(\%)$ & $76(73.1 \%$ of all 104 patients) \\
Clinical symptoms & $52(68.4)$ \\
Data of clinical symptoms available & $24(31.6)$ \\
Clinical symptoms present, $n(\%)$ & \\
Clinically asymptomatic, $n(\%)$ & 15 \\
Metastases & $5(33.3)$ \\
Patients with metastases & $10(66.6)$ \\
Synchronous metastases, $n$ (\%) & 3.6 \\
Metachronous metastases, $n(\%)$ & \\
Mean time of recurrence, years & $44(42.3)$ \\
Secondary neoplasia, $n$ (\%) & $32(72.7)$ \\
Secondary neoplasia in addition to GIST & $14(31.8)$ \\
$\quad$ Malignant neoplasia & $3(6.8)$ \\
$\quad$ Benign neoplasia &
\end{tabular}

(SD 11.85 years) and median age was 70 years. We calculated the approximate annual incidence of GISTs between 1999 and 2010 based on the population in WesternPomerania with a mean of 1.1 per 100,000 and a variance of 0.4-2.6 per 100,000. Mean follow-up for all patients was 30.9 months and was carried out for up to 180 months.

The mean tumor size in our cohort was $4.96 \mathrm{~cm}$ (range from 0.2 to $20 \mathrm{~cm}$ ). Histologically, more than $75 \%$ of all tumors showed a spindle cell configuration whereas epithelioid cell and mixed type pattern were found more rarely (Table 1).

\section{Localization of GISTs}

Data were available for almost all patients $(n=102)$. One patient had both gastric and an extraintestinal GIST (diaphragm). GISTs were widely distributed along the entire gastrointestinal tract. By far, the most frequent location was the stomach where around two-thirds of all tumors were found. It was found that $16.2 \%$ of all GISTs were located in the small intestine whereas only $2.9 \%$ of the tumors were found in the colorectum. Esophageal location was seen in $4.8 \%$. Extraintestinal manifestation was observed for 7 tumors corresponding to $6.7 \%$ of all GISTs (Table 2).
Table 2. Localization of GIST in the gastrointestinal tract and extraintestinal location

\begin{tabular}{lcc}
\hline Localization of GIST & Number & Percentage \\
\hline Stomach & 71 & 67.6 \\
Small intestine & 17 & 16.2 \\
Colorectum & 3 & 2.9 \\
Esophagus & 5 & 4.8 \\
eGIST & 7 & 6.7 \\
No data available & 2 & 1.9 \\
\hline Total & $105^{*}$ & 100 \\
\hline \multirow{2}{*}{$*$ Multiple locations found in 1 patient. } & \\
$\quad$ GIST, gastrointestinal stromal tumor; eGIST, extraintestinal \\
eGIST.
\end{tabular}

\section{Risk Stratification}

Based on tumor size, localization, and proliferation rate (mitotic index), tumor stage classification and risk assessment were performed. We used the classification systems of the AFIP [13], NIH [10], as well as the modified NIH criteria [11] and were able to classify 89 patients 
Table 3. Recurrence risk according to the classifications of Fletcher et al. [10], Miettinen et al. [13], and Joensuu et al. [11]

\begin{tabular}{llll}
\hline Recurrence risk & $\begin{array}{l}\text { NIH (Fletcher et al. [10], } \\
2002), n(\%)\end{array}$ & $\begin{array}{l}\text { AFIP (Miettinen et al. [13], } \\
\text { 2006), } n(\%)\end{array}$ & $\begin{array}{l}\text { Modified NIH (Joensuu } \\
\text { et al. [11], 2008), } n(\%)\end{array}$ \\
\hline Very low & $14(15.7)$ & $17(19.5)$ & $17(19.5)$ \\
Low & $30(33.7)$ & $43(49.4)$ & $28(32.2)$ \\
Intermediate & $23(25.8)$ & $6(6.9)$ & $18(20.7)$ \\
High & $22(24.7)$ & $21(24.1)$ & $24(27.6)$ \\
\hline Total & $89(100)$ & $87(100)$ & $87(100)$ \\
\hline
\end{tabular}

by NIH criteria and 87 by modified NIH and AFIP criteria, respectively. When classifying according to the most widely used AFIP system, more than half of patients were grouped to a low (49.4\%) or even very low (19.5\%) tumor recurrence risk (Table 3 ). The percentage of patients with a very low recurrence risk was comparable in all 3 classification systems. Low recurrence risk was more frequently seen $(49.4 \%)$ when applying the APIF criteria compared to the modified NIH criteria $(32.2 \%)$ or the initial consensus approach by Fletcher et al. [10] (33.7\%). In contrast, only $6.9 \%$ of patients had an intermediate tumor recurrence risk according to the AFIP criteria which was remarkably higher (20.7 and $25.8 \%$, respectively) after application of other classification systems. Numbers of patients having a high risk were quite comparable in all 3 classification systems (Table 3 ).

\section{Clinical Symptoms at First Diagnosis}

Data regarding presence of clinical symptoms of GIST patients at hospital admission were available for 76 out of 104 patients (73.1\%). Among them 52 patients (68.4\%) had symptoms, whereas the remainder was asymptomatic and diagnosis was established during routine examinations or accidentally during a diagnostic workup due to other reasons. We observed a variety of clinical symptoms that were often unspecific and not directly indicating an underlying tumor disease. Gastrointestinal bleeding was the most common reported clinical sign (55.8\%), followed by abdominal pain (38.5\%), weight loss (13.5\%), nausea/vomiting $(9.6 \%)$, heartburn (9.6\%), and dizziness (7.7\%; Table 4).

In a next step, clinical symptoms were analyzed in relation to tumor localization in order to clarify whether particular symptoms are associated with a specific tumor site. We only considered patients where both information on GIST localization and clinical symptoms were available (online suppl. Table 1; for all online suppl. material, see www.karger.com/doi/10.1159/000489556).
Table 4. Most frequently reported clinical symptoms of patients with GIST at first diagnosis (multicode allowed)

\begin{tabular}{ll}
\hline Symptom & Number of patients, $n(\%)$ \\
\hline Gastrointestinal bleeding & $29(55.8)$ \\
Abdominal pain & $20(38.5)$ \\
Weight loss & $7(13.5)$ \\
Weakness/dizziness & $7(13.5)$ \\
Heartburn & $5(9.6)$ \\
Nausea/vomiting & $5(9.6)$ \\
Loss of appetite & $2(3.8)$ \\
Dyspnea & $2(3.8)$ \\
Ileus & $2(3.8)$ \\
Feeling of fullness & $2(3.8)$ \\
\hline
\end{tabular}

Most data on symptoms were available for gastric GISTs since this tumor entity was the most common one. Gastrointestinal bleeding was most frequently reported by patients with GISTs of the stomach (64\%), the small intestine $(46.7 \%)$, and the colorectum (33.3\%), although the absolute number of patients with colorectal GISTs was quite low. Regarding tumors of the stomach, abdominal pain was reported by $28 \%$ of patients, whereas another $28 \%$ of patients did not report any clinical symptoms. Abdominal pain was also associated with tumors of other sites, as in 25\% for esophageal, $20 \%$ for small intestinal, and 50\% for extraintestinal GIST location but tumor prevalence was much lower compared to gastric location.

\section{Metastasis Formation of GISTs}

Patients were further analyzed for occurrence of metastases; 15 out of 104 patients were diagnosed with metastases, of which 5 (33.3\%) had synchronous and 10 $(66.6 \%)$ metachronous metastases. Patients with local tumor recurrence after surgery ( 2 individuals) were also included to the group with metachronous metastases. In all patients with synchronous and metachronous metas- 
Table 5. Presence of GIST metastases in relation to risk classifications of Fletcher et al. [10], Miettinen et al. [13], and Joensuu et al. [11]

\begin{tabular}{llllll}
\hline Recurrence risk & \multicolumn{2}{l}{ Number of patients, $n(\%)$} & & \\
\cline { 2 - 5 } & high risk & intermediate risk & low risk & very low risk & all \\
\hline $\begin{array}{l}\text { NIH } \\
\text { (Fletcher et al. [10], 2002) }\end{array}$ & $11(73.3)$ & $1(6.7)$ & $2(13.3)$ & $1(6.7)$ & $15(100)$ \\
\hline $\begin{array}{l}\text { AFIP } \\
\text { (Miettinen et al. [13], 2006) }\end{array}$ & $10(71.4)$ & $0(0)$ & $3(21.4)$ & $1(7.1)$ & $14(100)$ \\
\hline $\begin{array}{l}\text { Modified NIH } \\
\text { (Joensuu et al. [11], 2008) }\end{array}$ & $10(71.4)$ & $1(7.1)$ & $2(14.3)$ & $1(7.1)$ & $14(100)$ \\
\hline
\end{tabular}

tases, origin from a GIST was confirmed by histology. The mean time between initial GIST diagnosis and appearance of metastases was 3.6 years (ranging from 1 to 15 years). The most frequent location was the liver (10 of 15 patients, $66.7 \%$ ), rarer sites included the peritoneum ( 4 of $15,26.7 \%)$, bones ( 2 of $15,13.3 \%$ ), lymph nodes ( 2 of $15,13.3 \%)$, and pancreas and the colon (1 of 15, 6.7\%).

To determine independent variables for recurrencefree survival, Kaplan-Meier analyses were calculated using the categories tumor location (stomach, esophagus, small intestine, eGIST), size $(<5,5.1-10$ and $10.1-15 \mathrm{~cm})$, and mitotic index $(0-5,6-10,>10$ mitoses/high power field). Small tumors $(<5 \mathrm{~cm})$ and those with a low mitotic index $(<5 /$ high power field) were associated with a lower disease-free survival. No clear association was found for tumor location acknowledging a small patient size as a limiting factor (online suppl. Fig. 1).

Next, we compared patients with synchronous or metachronous metastases by using the commonly used risk classifications in order to determine the accuracy of predicting metastatic disease. Again we used the NIH, modified NIH, and AFIP criteria that were available for 15 and 14 patients, respectively (Table 5). As expected, the majority of patients with metastases belonged to the high risk group (71.4 and $73.3 \%$ ), irrespective of the classification system used. Only 1 patient belonged to the group with an intermediate risk when using the criteria by Fletcher (6.6\%) and Joensuu (7.1\%). Around 20\% belonged to the low and very low risk group and this number was even higher when applying the criteria of Miettinen (28.5\%). In consideration of all patients (Table 3), a tumor progression was noted for $41.6-50 \%$ of the high risk group, $0-5.6 \%$ of the intermediate group, $6.7-7.1 \%$ of the low risk group, and $5.9-7.1 \%$ of the very low risk group patients, depending on the risk classification that was applied.

Gastrointestinal Stromal Tumors in a Single Center
Secondary Malignant Lesions in GIST Patients

Various malignancies are known to be associated with an increased rate of malignant tumors at other, unrelated sites. Secondary neoplasias may precede or succeed the index admission for GIST or are detected simultaneously. We studied how many GIST patients suffered from a secondary neoplasm and which kind of tumor they had developed during the same observation period; 44 patients (42.3\%) were diagnosed with a secondary tumor of any kind (benign, semi-malignant, or malignant) in addition to the GIST. In 32 patients (30.8\%), 38 malignant tumors were found. Among them, 9 tumors were known for at least 1 year before diagnosis of GIST, while $18 \mathrm{tu}$ mors were diagnosed within the time period of \pm 1 year of index admission for GIST and 9 malignant tumors were diagnosed at least 1 year after the diagnosis of a GIST. In 2 cases, the exact time of diagnosis of the secondary neoplasm could not be retrieved retrospectively. Among them, 26 individuals had 1 additional malignancy and 6 patients 2 more malignant tumors. Moreover, 15 benign tumors were detected in 14 patients (13.5\%) and 3 semi-malignant tumors (basal cell carcinoma) were found in 3 patients (2.9\%). Combinations of either benign, semi-malignant, or malignant tumors existed in 5 patients.

The number and site of malignant neoplasias are shown in Table 6. Carcinomas of the gastrointestinal tract were observed most frequently (52.6\%) followed by tumors of the urogenital tract $(21.1 \%)$ and the mammary gland (18.4\%). Regarding organ involvement, secondary malignancies were most often seen in the colon $(26.3 \%)$ and the stomach and the prostate (15.8\%). Rarer entities were hematologic neoplasias (5.3\%) and a peripheral nerve sheath tumor (2.6\%), a type of sarcoma originating from the surrounding tissue of nerves. 
Table 6. Occurrence and site of secondary malignant neoplasms in our cohort and comparison to literature

\begin{tabular}{|c|c|c|c|c|}
\hline & & $\begin{array}{l}\text { Our cohort number } \\
\text { of tumors, } n(\%)\end{array}$ & $\begin{array}{l}\text { Pandurengan et al. [1], } \\
2010, n(\%)\end{array}$ & $\begin{array}{l}\text { Agaimy et al. [41], } \\
2006, n(\%)\end{array}$ \\
\hline \multirow[t]{4}{*}{ Carcinoma of the urogenital tract } & All & $8(21.1)$ & $62(33)$ & $111(23)$ \\
\hline & Prostate cancer & $6(15.8)$ & $28(15)$ & $43(9)$ \\
\hline & Kidney cancer & $1(2.6)$ & $12(6.5)$ & $27(6)$ \\
\hline & Urothelial cancer & $1(2.6)$ & $7(3.8)$ & $10(2)$ \\
\hline \multirow[t]{5}{*}{ Carcinoma of the gastrointestinal tract } & All & $20(52.6)$ & $48(26)$ & $228(47)$ \\
\hline & Colorectal cancer & $10(26.3)$ & $18(9.7)$ & $109(22)$ \\
\hline & Pancreatic cancer & $3(7.9)$ & $5(2.7)$ & $11(2)$ \\
\hline & Gastric cancer & $6(15.8)$ & $5(2.7)$ & $95(19)$ \\
\hline & Gallbladder cancer & $1(2.6)$ & $1(0.5)$ & $4(1)$ \\
\hline Breast cancer & & $7(18.4)$ & $15(8)$ & $34(7)$ \\
\hline Hematologic neoplasia & $\begin{array}{l}\text { Lymphoma/ } \\
\text { leukemia }\end{array}$ & $2(5.3)$ & $12(6.5)$ & $36(7)$ \\
\hline Malignant peripheral nerve sheath tumor & & $1(2.6)$ & NA & NA \\
\hline Total number of additional malignancies & & $38(100)$ & $186(100)$ & $518(100)$ \\
\hline
\end{tabular}

NA, not available.

\section{Discussion}

GISTs are common mesenchymal neoplasias of the gastrointestinal tract. Within the last decades, much progress has been made not only in understanding the molecular biology of these tumors but also regarding diagnostic and therapeutic options [25].

Here we characterized GIST patients from a tertiary care hospital in north-eastern Germany diagnosed between 1993 and 2011. On the one hand, we focused on clinical symptoms of these patients in relation to the tumor localization, and on the other hand, we studied metastasis formation and the association with secondary malignancies.

In our cohort, the calculated annual incidence of GISTs was between 0.4 and 2.6 per 100,000 and thus in line with reported data from other groups, especially from northwestern Europe (The Netherlands, Sweden, Iceland) where it ranged from 0.7 to 2.0 per $100,000[7,26,27]$. Since our hospital is the only tertiary referral center in Western Pomerania, a rural area in north-eastern Germany with a population of around 700,000 inhabitants [23], it is a well suited area to make near populationbased assessments, because nearly all patients are referred to this hospital. Secondly, the study population was well defined and histology was available for patients from the same team of pathologists. In our cohort, the mean age at first diagnosis of GIST was slightly higher (66.86 years) compared to other series reporting a range between 57.8 and 65 years [28-30]. This may be due to a slightly older population in north-eastern Germany compared to the rest of the country being more than 3 years above the mean [31-34]. Another reason for the later age at diagnosis may be a more limited access to specialist care in this rural area.

As outlined by the AFIP tumor size, mitotic index and location are prognostic factors for this tumor entity. In our study, the mean tumor size was $4.96 \mathrm{~cm}$ and thus quite comparable to another population-based study on GISTs from Europe [27]. Around two-thirds (67.6\%) were located in the stomach, consistent to other groups who indicated gastric GISTs being the most frequent stromal tumor in $40-60 \%$ of cases. Tumor manifestation in the small intestine was seen in $16.2 \%$, compared to studies that found jejunal or ileal stromal tumors in 20 $50 \%$ of patients $[15,19,35]$. In contrast to the small intestine, a colorectal manifestation is rarely observed having an incidence of $4.0-6.4 \%$ and thus slightly higher than in our cohort (2.9\%) [15, 19, 21, 35]. Esophageal location was comparably very low to other studies (mostly $<5 \%$ ), the same was true for extraintestinal GISTs. Data for extraintestinal GISTs were rather scarce. In a large monocentric study of 200 patients with GIST, an extraintestinal location was seen in $8 \%$ whereby they also included esophageal tumors in that entity [29].
Dig Dis

DOI: $10.1159 / 000489556$
Aghdassi/Christoph/Dombrowski/ Döring/Barth/Christoph/Lerch/Simon 
A considerable number of our patients (around 30\%) remained clinically asymptomatic. In these patients, diagnosis was often established either by radiologic, ultrasound, or endoscopic examinations done for reasons other than a suspected tumor, during an operation, or in surgical specimens after bariatric surgery. The frequency of asymptomatic GIST patients is in line with other studies that reported an incidence of 10-30\% [35]. Establishing the diagnosis of GIST is still challenging as these tumors do not have a specific clinical manifestation. Moreover, symptoms depend on tumor size and can be observed in other gastrointestinal disorders as well [36]. In addition, some patients present with more than 1 clinical sign. In our cohort, common symptoms were gastrointestinal bleeding including either hematemesis, hematochezia, melena or a positive stool blood test (55.8\%), abdominal pain (38.5\%), weight loss, or a general feeling of weakness and dizziness (each 13.5\%). These observations were in line with other series that found comparable results $[15,21,36,37]$.

We were further interested in whether specific clinical symptoms of GIST patients may predict tumor location. For gastric GISTs, the largest subgroup, gastrointestinal bleeding was by far the most common reported symptom (64\%) and more frequently observed than for other GIST locations. Abdominal pain was less often seen when compared to all GISTs together ( 28 vs. $38.5 \%$ ). The absence of clinical symptoms was often noted when tumor site was in the esophagus, small, or large intestine. However, numbers of patients in the latter subgroups were rather small so that these results have to be interpreted with caution. Our results confirm observations from Caterino et al. [21] who found that bleeding in the digestive tract was more frequent in gastric GISTs than for other localizations. Abdominal pain was observed almost as often as bleeding which differs to our results [21]. However, their patient cohort was smaller. In addition, as in our study, the authors were also confronted with a low case load for extra-gastric stromal tumors making representative statistics more difficult.

An accurate prediction of the biological behavior of GISTs is challenging. The majority of our tumors were classified with a low or very low recurrence risk independent of the type of classification that was used. Around onequarter of patients belonged to the high risk group (24.1$27.6 \%)$. Regarding metastasis formation only 15 out of 104 (14.4\%) patients were diagnosed with metastatic disease. Among them two-thirds had metachronous and one-third synchronous metastases. We compared the presence of metastases to the most commonly used risk classification systems in order to see accuracy of prediction. As expected, more than $70 \%$ of patients with metastases belonged to the

Gastrointestinal Stromal Tumors in a

Single Center high risk group. Only a minority of patients were classified as intermediate or very low risk. In contrast to our expectations, our data show that even $13.3-21.4 \%$ of metastasized patients belonged to the low risk group.

A recently published large single center study $(n=497)$ investigating tumor recurrence in GIST patients found a slightly higher risk of overall tumor recurrence or metastasis formation which was $19.7 \%$ [38]. However, hardly any tumor relapse was observed in the low risk and very low risk groups. There may be various reasons explaining this discrepancy. One is that our study contained a higher proportion of low and very low risk GIST cases. Secondly, there may be differences regarding the time of tumor diagnosis, operation, and adjuvant chemotherapy between the centers that may influence recurrence rates. Further studies will be necessary to elucidate this question. In addition, the absolute number of patients with metastasis formation or tumor recurrence was low in the low risk categories making a universal conclusion difficult. In a large meta-analysis of population-based studies including 2,560 GIST patients and a validation series of 920 patients, Joensuu et al. [39] identified the modified NIH classification as most suitable criteria for identification of high risk groups among the commonly used classification systems. Secondly, they developed a new method for estimation of GIST recurrence by including tumor localization and rupture status and respecting the non-linear effect of mitosis and tumor size on recurrence-free survival. Our data showed that NIH criteria predicted tumor recurrence (73.3\%) slightly better than modified NIH criteria and AFIP criteria (71.4\%); however, only 15 of our patients had metastases.

Besides metastasis formation, the occurrence of secondary neoplasms worsens the prognosis of GIST patients. There is evidence that coexisting secondary neoplasms appear more often in GIST patients than in the general population $[1,40]$ and an association of GISTs with both solid and hematologic tumors were reported. The overall frequency of secondary tumors varies from 4.5 to $33 \%$ with a mean of $13 \%$ [1, 41]. According to Agaimy et al. [41], gastric cancer (47\%), prostate cancer $(9 \%)$, breast cancer or lymphoma, as well as leukemia (both 7\%) were reported in association with GISTs, followed by kidney (6\%) and lung cancer (5\%) as well as tumors of the female reproductive tract (5\%). In a large single center study of 783 patients, $20 \%$ were diagnosed with at least 1 additional primary [1] and the majority of tumors were of genitourinary (33\%) or gastrointestinal $(26 \%)$ origin. To a lesser extent, breast cancer (8\%) and hematologic neoplasias (6.5\%) were seen. In our series, more than $40 \%$ of GIST patients were diagnosed with an 
additional tumor, irrespective of dignity. A malignant secondary neoplasia was observed in $30.8 \%$ and thus being in the upper range of reported prevalences. Three patients (2.9\%) had diagnosis of both a benign and a malignant neoplasia. Potential reasons for our comparatively high number of secondary neoplasms are a longer followup time in our study that was up to 15 years and a much higher mean age of our study population which was around 67 years at the first diagnosis of GIST, and thus more than 10 years older than in the aforementioned study [1]. In addition, our patient group was exclusively of Caucasian ancestry. Our data support the high incidence of secondary GI neoplasms in GIST patients, especially colorectal, gastric, and pancreatic cancer.

There are limitations of our study. The retrospective setting caused missing data that we had to correct for when analyzing histopathology and clinical symptoms. Information on clinical signs was unavailable for about $25 \%$ of patients. Therefore, a subgroup analysis of symptoms depending on GIST localization is challenging due to small numbers. In addition, reporting of patient's complaints in a retrospective analysis has limitations as they have to be retrieved from the patient file which might be incomplete. Reporting of symptoms in a prospective design would be a superior approach. Secondly, a comprehensive characterization of GISTs needs to include an analysis of genetic changes that are likely to further affect survival [42]. Larger, preferably multicenter studies will be necessary to determine symptoms depending on tumor location, especially for extra-gastric tumor sites. Moreover, the small number of patients limits the calculation of probability of disease recurrence after surgery, since follow-up data were available for only 39 patients and ex- act time of death was known for 12 patients. Metachronous metastases were detected in only 10 patients. Larger studies with pooled data will be an ideal approach for estimation of GIST recurrence as published previously [39].

In summary, we presented a clinical characterization of a single center cohort of GIST patients. Clinical symptoms correlated with tumor location, most remarkably for gastric location. There was a considerable risk for tumor recurrence, metastasis formation, and the occurrence of secondary malignant tumors. A comparably higher risk for metastases was detected especially in low risk patients. These observations have clinical implications. First, even patients in lower risk groups may benefit from follow-up examinations, although it remains unclear whether this is cost-effective, and secondly, GIST patients with their increased risk of developing secondary tumors at unrelated sites may benefit from surveillance and screening programs for colorectal, breast, and prostate cancer.

\section{Acknowledgments}

We thank Maria Valentin and Katja Evert for their technical assistance. This work was supported by the Deutsche Krebshilfe/ Dr. Mildred-Scheel-Stiftung (109102), the Deutsche Forschungsgemeinschaft (DFG GRK1947, A3, AG 203/2-1), the Federal Ministry of Education and Research (BMBF GANI-MED 03IS2061A and BMBF 0314107, 01ZZ9603, 01ZZ0103, 01ZZ0403, 03ZIK012) and the European Union (EU-FP-7: EPC-TM and EU-FP7-REGPOT-2010-1).

\section{Disclosure Statement}

The authors declare no conflicts of interest.

\section{References}

1 Pandurengan RK, Dumont AG, Araujo DM, Ludwig JA, Ravi V, Patel S, Garber J, Benjamin RS, Strom SS, Trent JC: Survival of patients with multiple primary malignancies: A study of 783 patients with gastrointestinal stromal tumor. Ann Oncol 2010;21:2107-2111.

2 Min KW, Leabu M: Interstitial cells of cajal (icc) and gastrointestinal stromal tumor (gist): facts, speculations, and myths. J Cell Mol Med 2006;10:995-1013.

3 Miettinen M, Lasota J: Gastrointestinal stromal tumors: Review on morphology, molecular pathology, prognosis, and differential diagnosis. Arch Pathol Lab Med 2006;130: 1466-1478.

4 Esposito I, Schlitter AM: Pathology of neuroendocrine neoplasias (nen) und gastrointes- tinal stromal tumors (gist) (article in german). Der Gastroenterologe 2015;10:394409.

5 Hirota S, Isozaki K, Moriyama Y, Hashimoto K, Nishida T, Ishiguro S, Kawano K, Hanada $M$, Kurata A, Takeda M, Muhammad Tunio G, Matsuzawa Y, Kanakura Y, Shinomura Y, Kitamura Y: Gain-of-function mutations of c-kit in human gastrointestinal stromal tumors. Science 1998;279:577580.

66 Group ESESNW: Gastrointestinal stromal tumours: Esmo clinical practice guidelines for diagnosis, treatment and follow-up. Ann Oncol 2014;25(suppl 3):iii21-iii26.

7 Goettsch WG, Bos SD, Breekveldt-Postma $\mathrm{N}$, Casparie M, Herings RM, Hogendoorn
PC: Incidence of gastrointestinal stromal tumours is underestimated: results of a nationwide study. Eur J Cancer 2005;41:28682872.

8 Tran T, Davila JA, El-Serag HB: The epidemiology of malignant gastrointestinal stromal tumors: an analysis of 1,458 cases from 1992 to 2000. Am J Gastroenterol 2005;100:162-168.

-9 Joensuu H: Gastrointestinal stromal tumor (gist). Ann Oncol 2006;17(suppl 10):x280$\mathrm{x} 286$.

-10 Fletcher CD, Berman JJ, Corless C, Gorstein F, Lasota J, Longley BJ, Miettinen M, O'Leary TJ, Remotti H, Rubin BP, Shmookler B, Sobin LH, Weiss SW: Diagnosis of gastrointestinal stromal tumors: a consensus approach. Hum Pathol 2002;33:459-465.
8
Dig Dis

DOI: $10.1159 / 000489556$
Aghdassi/Christoph/Dombrowski/ Döring/Barth/Christoph/Lerch/Simon 
11 Joensuu H: Risk stratification of patients diagnosed with gastrointestinal stromal tumor. Hum Pathol 2008;39:1411-1419.

12 TNM Classification of Malignant Tumors, (ed 7). Sobin LH (Ed.), Gospodarowicz MK (Ed.), Wittekind C (Ed.), Wiley-Blackwell, 2009.

13 Miettinen M, Lasota J: Gastrointestinal stromal tumors: pathology and prognosis at different sites. Semin Diagn Pathol 2006;23:70-83.

14 Joensuu H, Hohenberger P, Corless CL: Gastrointestinal stromal tumour. Lancet 2013; 382:973-983.

- 15 Yao KA, Talamonti MS, Langella RL, Schindler NM, Rao S, Small W Jr, Joehl RJ: Primary gastrointestinal sarcomas: analysis of prognostic factors and results of surgical management. Surgery 2000;128:604-612.

-16 Joensuu H, Eriksson M, Sundby Hall K, Hartmann JT, Pink D, Schutte J, Ramadori G, Hohenberger P, Duyster J, Al-Batran SE, Schlemmer M, Bauer S, Wardelmann E, Sarlomo-Rikala M, Nilsson B, Sihto H, Monge OR, Bono P, Kallio R, Vehtari A, Leinonen M, Alvegard T, Reichardt $P$ : One vs three years of adjuvant imatinib for operable gastrointestinal stromal tumor: a randomized trial. JAMA 2012;307:1265-1272.

- 17 Demetri GD, van Oosterom AT, Garrett CR, Blackstein ME, Shah MH, Verweij J, McArthur G, Judson IR, Heinrich MC, Morgan JA, Desai J, Fletcher CD, George S, Bello CL, Huang X, Baum CM, Casali PG: Efficacy and safety of sunitinib in patients with advanced gastrointestinal stromal tumour after failure of imatinib: a randomised controlled trial. Lancet 2006;368:1329-1338.

-18 Demetri GD, Reichardt P, Kang YK, Blay JY, Rutkowski P, Gelderblom H, Hohenberger P, Leahy M, von Mehren M, Joensuu H, Badalamenti G, Blackstein M, Le Cesne A, Schoffski P, Maki RG, Bauer S, Nguyen BB, Xu J, Nishida T, Chung J, Kappeler C, Kuss I, Laurent D, Casali PG; GRID study investigators: Efficacy and safety of regorafenib for advanced gastrointestinal stromal tumours after failure of imatinib and sunitinib (grid): an international, multicentre, randomised, placebo-controlled, phase 3 trial. Lancet 2013;381:295-302.

19 Beham AW, Schaefer IM, Schuler P, Cameron S, Ghadimi BM: Gastrointestinal stromal tumors. Int J Colorectal Dis 2012;27:689-700.

20 Liu YJ, Yang Z, Hao LS, Xia L, Jia QB, Wu XT: Synchronous incidental gastrointestinal stromal and epithelial malignant tumors. World J Gastroenterol 2009;15:2027-2031.

-21 Caterino S, Lorenzon L, Petrucciani N, Iannicelli E, Pilozzi E, Romiti A, Cavallini M, Ziparo V: Gastrointestinal stromal tumors: correlation between symptoms at presentation, tumor location and prognostic factors in 47 consecutive patients. World J Surg Oncol 2011;9:13.

22 Miettinen M: Gastrointestinal stromal tumors: an immunohistochemical study of cellular differentiation. Am J Clin Pathol 1988; 89:601-610.

23 Amt MVS: Veröffentlichungen - Statistisches Amt Mecklenburg-Vorpommern, 2015.
24 Athey BD, Braxenthaler M, Haas M, Guo Y: Transmart: an open source and communitydriven informatics and data sharing platform for clinical and translational research. AMIA Jt Summits Transl Sci Proc 2013; 2013:6-8.

25 Watson GA, Kelly D, Melland-Smith M, Gleeson J, McEntee G, Kelly CM, McCaffrey JA: Get the gist? An overview of gastrointestinal stromal tumours. Ir J Med Sci 2016;185: 319-326.

26 Nilsson B, Bumming P, Meis-Kindblom JM, Oden A, Dortok A, Gustavsson B, Sablinska $\mathrm{K}$, Kindblom LG: Gastrointestinal stromal tumors: the incidence, prevalence, clinical course, and prognostication in the preimatinib mesylate era - a population-based study in western sweden. Cancer 2005; 103:821829.

-27 Tryggvason G, Gislason HG, Magnusson MK, Jonasson JG: Gastrointestinal stromal tumors in iceland, 1990-2003: the icelandic gist study, a population-based incidence and pathologic risk stratification study. Int J Cancer 2005;117:289-293.

28 Antonescu CR, Sommer G, Sarran L, Tschernyavsky SJ, Riedel E, Woodruff JM, Robson M, Maki R, Brennan MF, Ladanyi M, DeMatteo RP, Besmer P: Association of kit exon 9 mutations with nongastric primary site and aggressive behavior: kit mutation analysis and clinical correlates of 120 gastrointestinal stromal tumors. Clin Cancer Res 2003;9:3329-3337.

29 DeMatteo RP, Lewis JJ, Leung D, Mudan SS, Woodruff JM, Brennan MF: Two hundred gastrointestinal stromal tumors: recurrence patterns and prognostic factors for survival. Ann Surg 2000;231:51-58.

-30 Miettinen M, Sarlomo-Rikala M, Sobin LH, Lasota J: Gastrointestinal stromal tumors and leiomyosarcomas in the colon: a clinicopathologic, immunohistochemical, and molecular genetic study of 44 cases. Am J Surg Pathol 2000;24:1339-1352.

31 Bundesamt S: Fachserie 1, Reihe 1.3, Bevölkerung und Erwerbstätigkeit. Wiesbaden, Statistisches Bundesamt, 2016.

32 Volzke H, Alte D, Schmidt CO, Radke D, Lorbeer R, Friedrich N, Aumann N, Lau K, Piontek M, Born G, Havemann C, Ittermann T, Schipf S, Haring R, Baumeister SE, Wallaschofski H, Nauck M, Frick S, Arnold A, Junger M, Mayerle J, Kraft M, Lerch MM, Dorr M, Reffelmann T, Empen K, Felix SB, Obst A, Koch B, Glaser S, Ewert R, Fietze I, Penzel T, Doren M, Rathmann W, Haerting J, Hannemann M, Ropcke J, Schminke U, Jurgens C, Tost F, Rettig R, Kors JA, Ungerer S, Hegenscheid K, Kuhn JP, Kuhn J, Hosten N, Puls R, Henke J, Gloger O, Teumer A, Homuth G, Volker U, Schwahn C, Holtfreter B, Polzer I, Kohlmann T, Grabe HJ, Rosskopf D, Kroemer HK, Kocher T, Biffar R, John U, Hoffmann W: Cohort profile: the study of health in pomerania. Int J Epidemiol 2011;40: 294-307.
33 Grabe HJ, Assel H, Bahls T, Dorr M, Endlich K, Endlich N, Erdmann P, Ewert R, Felix SB, Fiene B, Fischer T, Flessa S, Friedrich N, Gadebusch-Bondio M, Salazar MG, Hammer E, Haring R, Havemann C, Hecker M, Hoffmann W, Holtfreter B, Kacprowski T, Klein K, Kocher T, Kock H, Krafczyk J, Kuhn J, Langanke M, Lendeckel U, Lerch MM, Lieb W, Lorbeer R, Mayerle J, Meissner K, zu Schwabedissen HM, Nauck M, Ott K, Rathmann W, Rettig R, Richardt C, Salje K, Schminke U, Schulz A, Schwab M, Siegmund W, Stracke S, Suhre K, Ueffing M, Ungerer S, Volker U, Volzke H, Wallaschofski H, Werner V, Zygmunt MT, Kroemer HK: Cohort profile: greifswald approach to individualized medicine (gani_med). J Transl Med 2014;12: 144.

-34 Lerch MM, Braun J, Harder M, Hofstadter F, Schumpelick V, Matern S: Postoperative adaptation of the small intestine after total colectomy and j-pouch-anal anastomosis. Dis Colon Rectum 1989;32:600-608.

- 35 Cichoz-Lach H, Kasztelan-Szczerbinska B, Slomka M: Gastrointestinal stromal tumors: Epidemiology, clinical picture, diagnosis, prognosis and treatment. Pol Arch Med Wewn 2008;118:216-221.

36 Liu Q, Wang Y, Kong L, Kan Y: Study on clinicopathological features of gastrointestinal stromal tumor and relevant prognostic factors. Cell Biochem Biophys 2015;73:743-747.

-37 Al-Thani H, El-Menyar A, Rasul KI, Al-Sulaiti M, El-Mabrok J, Hajaji K, Elgohary H, Tabeb A: Clinical presentation, management and outcomes of gastrointestinal stromal tumors. Int J Surg 2014;12:1127-1133.

38 Wang $\mathrm{M}, \mathrm{Xu}$ J, Zhang Y, Tu L, Qiu WQ, Wang CJ, Shen YY, Liu Q, Cao H: Gastrointestinal stromal tumor: 15-years' experience in a single center. BMC Surg 2014;14:93.

- 39 Joensuu H, Vehtari A, Riihimaki J, Nishida T, Steigen SE, Brabec P, Plank L, Nilsson B, Cirilli C, Braconi C, Bordoni A, Magnusson MK, Linke Z, Sufliarsky J, Federico M, Jonasson JG, Dei Tos AP, Rutkowski P: Risk of recurrence of gastrointestinal stromal tumour after surgery: an analysis of pooled populationbased cohorts. Lancet Oncol 2012;13:265274.

40 Wronski M, Ziarkiewicz-Wroblewska B, Gornicka B, Cebulski W, Slodkowski M, Wasiutynski A, Krasnodebski IW: Synchronous occurrence of gastrointestinal stromal tumors and other primary gastrointestinal neoplasms. World J Gastroenterol 2006;12:53605362.

41 Agaimy A, Wunsch PH, Sobin LH, Lasota J, Miettinen M: Occurrence of other malignancies in patients with gastrointestinal stromal tumors. Semin Diagn Pathol 2006;23:120129.

42 Miettinen M, Lasota J: Gastrointestinal stromal tumors - definition, clinical, histological, immunohistochemical, and molecular genetic features and differential diagnosis. Virchows Arch 2001;438:1-12.
Gastrointestinal Stromal Tumors in a Single Center 